\title{
Plasmidic CpG sequences induce tumor microenvironment modifications in a rat liver metastasis model
}

\author{
SAMUEL BERTIN $^{1}$, FABIENNE ANJUERE ${ }^{2}$, ADOLFO GAVELLI ${ }^{1,3}$, \\ PATRICK BAQUE ${ }^{1,4}$, BABOU KARIMDJEE SOILIHI ${ }^{1,5}$, NICOLE BROSSETTE ${ }^{1}$, \\ AGNES LOUBAT $^{1}$ and VALERIE PIERREFITE-CARLE ${ }^{1}$
}

\begin{abstract}
${ }^{1}$ INSERM Unité $638,{ }^{2}$ INSERM Unité 721, Université de Nice Sophia Antipolis, Faculté de Médecine, Avenue de Valombrose, F-06107 Nice Cédex 2, France; ${ }^{3}$ Service de Chirurgie Générale et Digestive, Centre Hospitalier Princesse Grace, MC-98012 Monaco, Monaco; ${ }^{4}$ Service de Chirurgie d'Urgence, Hôpital St Roch, Rue Pierre Devoluy, F-06107 Nice; ${ }^{5}$ Service de Chirurgie Générale et Cancérologie Digestive, Hôpital l'Archet 2, Route St Antoine de Ginestière, F-06200 Nice, France
\end{abstract}

Received September 26, 2007; Accepted November 9, 2007

\begin{abstract}
Bacterial DNA contains unmethylated cytosinephosphate-guanine $(\mathrm{CpG})$ motifs which are recognized by mammalian immune cells as a danger signal indicating an infection. These immunostimulatory properties led to the use of oligodeoxynucleotides bearing $\mathrm{CpG}$ motifs ( $\mathrm{CpG}-\mathrm{ODN}$ ) for cancer treatment in preclinical and clinical studies. Although naked DNA administration presently represents $18 \%$ of the gene therapy clinical trials worldwide, most of the work regarding the effects of unmethylated $\mathrm{CpG}$ sequences was performed using CpG-ODN. In the present study, we analyzed early induced tumor microenvironment modifications in a rat liver metastasis model after intratumoral injection of a plasmid used in suicide gene therapy. We first showed that plasmidic $\mathrm{CpG}$ motifs were active, i.e. able to induce IFN- $\gamma$ secretion by rat splenocytes. Then, we compared tumorinfiltrating immune cells $24 \mathrm{~h}$ after injection of native or Sss I-treated plasmid, in which immunostimulatory CpG motifs have been inactivated by methylation. The presence of active plasmidic $\mathrm{CpG}$ sequences within the tumor was associated with a decrease in the number of tumor-infiltrating conventional dendritic cells and an upregulation of the CCR7 chemokine receptor responsible for lymph node homing. We also observed an increase in plasmacytoid dendritic cells and natural killer cell infiltration within the tumors as well as an increased mRNA expression of three cytokines/chemokines (IL-1ß, IL-10 and IL-18). These data suggest that, although suicide plasmid injection without prodrug treatment is not sufficient
\end{abstract}

Correspondence to: Dr Valérie Pierrefite-Carle, Unité INSERM 638, Faculté de Médecine, Avenue de Valombrose, F-06107 Nice Cédex 2, France

E-mail: pierrefi@unice.fr

Key words: gene therapy, plasmid DNA, cytosine-phosphateguanine, Toll-like receptor 9 , colon carcinoma to observe a therapeutic effect, the presence of plasmidic CpG motifs within the tumor induces the recruitment and activation of the immune cells involved in antitumor response. These early cellular and molecular events should facilitate the induction of the immune response against tumor antigens released after in situ drug production.

\section{Introduction}

Colon carcinoma remains a leading cause of cancer death due to the development of liver metastases. As surgery, which constitutes the only curative treatment, can be performed in only $10 \%$ of metastatic patients $(1,2)$, an alternative treatment such as gene therapy needs to be developed. In this context, we developed a suicide gene therapy approach using the bacterial cytosine deaminase (CD) gene to convert the nontoxic antifungal agent 5-fluorocytosine (5-FC) into the widely used chemotherapeutic drug 5-fluorouracil (5-FU) (3).

We previously demonstrated, in a syngeneic rat bifocal liver metastasis model, that injection of a CD-expressing plasmid in one of the tumors, followed by 5-FC treatment of the animals, resulted in the regression of both lesions due to the triggering of a strong distant bystander effect (4). Although plasmid DNA injection without prodrug treatment was not sufficient to induce a therapeutic effect in this model (4), plasmid DNA could be involved in the potent antitumoral response observed via the presence of unmethylated $\mathrm{CpG}$ sequences in the plasmid backbone. Indeed, plasmid DNA, as bacterial DNA, contains unmethylated cytosine-phosphateguanine $(\mathrm{CpG})$ sequences that are considered immunostimulatory. $\mathrm{CpG}$ motifs are 4 times more frequent in bacterial than in mammalian DNA, and they are generally methylated in mammals and unmethylated in bacteria (5). These differences lead the immune system to recognize unmethylated $\mathrm{CpG}$ sequences as a 'danger signal' indicating a potential pathogen infection (5). In immune cells, recognition of these motifs mediated by the Toll-like receptor 9 (TLR9) (6) is followed by downstream signaling events leading to the activation of transcription and translation of target genes (7). As a 
consequence, bacterial $\mathrm{CpG}$ motifs trigger pleiotropic effects in immune cells such as proliferation, activation and cytokine/ chemokine secretion (5). An intratumoral injection of $\mathrm{CpG}$ oligonucleotides (CpG-ODN), which mimic bacterial DNA, was shown to exert antitumoral effects in various experimental tumor models (8-11). This therapeutic effect involving $\mathrm{CD}^{+}$ $\mathrm{T}$ cells or natural killer $(\mathrm{NK})$ cell activation can also induce the recruitment of macrophages or dendritic cells (DCs) within the tumor $(9,10)$ or in draining lymph nodes $(11)$.

As most of the work regarding the effects of unmethylated $\mathrm{CpG}$ sequences was performed using $\mathrm{CpG-ODN}$ and naked DNA administration presently represents $18 \%$ of the clinical trials worldwide (Wiley website 2007; http://www.wiley.co. $\mathrm{uk} / \mathrm{genmed} / \mathrm{clinical} /$ ), we investigated the plasmidic $\mathrm{CpG}$ effects in vivo. To this aim and towards prospective future clinical trials, we analyzed the cellular and molecular events early induced in vivo after intratumoral injection of the CDexpressing plasmid with or without functional $\mathrm{CpG}$ sequences in a metastatic colon carcinoma model.

\section{Materials and methods}

Plasmid and $C p G-O D N$. The pCDßgeo plasmid contains the cytosine deaminase (CD) gene under the control of the CMV promoter and a neo-lacZ fusion gene located downstream from the PGK promoter (3). Plasmid DNA was prepared using the Qiagen EndoFree Plasmid Mega Kit (Qiagen, Courtaboeuf, France) according to the manufacturer's instructions (endotoxins $<0.1 \mathrm{EU} / \mu \mathrm{g}$ of DNA). Phosphorothioate-modified oligonucleotides (ODNs) were purchased from Proligo (Paris, France). The following sequences were used (the underlined letters indicate the $\mathrm{CpG}$ motifs or the $\mathrm{CpC}$ motifs of the negative control ODN). CpG-ODN 1826, 5'-TCCATGACGTTCCTGACGTT-3' and CpC-ODN, 5'TCCATGACCTTCCTGACCTT-3'.

Plasmid methylation. The pCDßgeo plasmid (200 $\mu \mathrm{g}$ in a $1-\mathrm{ml}$ final volume) was methylated with SssI CpG methylase (New England Biolabs, Ozyme, St Quentin en Yvelines, France) at $2 \mathrm{U}$ enzyme $/ \mu \mathrm{g}$ of DNA for $4 \mathrm{~h}$ at $37^{\circ} \mathrm{C}$, according to the manufacturer's instructions. DNA was then extracted with phenol/chloroform, precipitated with ethanol, and washed with $70 \%$ ethanol. Methylated plasmid (Met-P) was quantified, and the efficiency of methylation was confirmed by BstUIdigestion. The native pCDßgeo plasmid (P) was subjected to the same treatment except that SssICpG methylase was omitted in the reaction mix.

Cell culture. DHD/K12/PROb (PROb) cells constitute a colon carcinoma cell line originating from a chemically induced colon cancer in BDIX rats (12). These cells are poorly immunogenic and induce progressive and metastatic tumors in syngeneic hosts. PROb cells were maintained in Dulbecco's modified Eagle's medium (Invitrogen, Cergy Pontoise, France) supplemented with $10 \%$ fetal calf serum (Dutscher, Brumath, France), 50,000 UI/1 penicillin, $100 \mu \mathrm{mol} / 1$ streptomycin, $2 \mathrm{mmol} / \mathrm{l} \mathrm{L}$-glutamine at $37^{\circ} \mathrm{C}$ and in $8 \% \mathrm{CO}_{2}$. For generation of liver tumors, cells were trypsinized, washed and resuspended at $15 \times 10^{6}$ cells $/ \mathrm{ml}$ in cold phosphate-buffered saline. For measurement of in vitro cytokine production, rat splenocytes $\left(10^{6}\right.$ cells in $200 \mu \mathrm{l} /$ well $)$ were cultured in standard 48-well plates in RPMI-1640 (Cambrex, Vervier, Belgium) supplemented with $10 \%$ fetal calf serum, 50,000 UI/1 penicillin, $100 \mu \mathrm{mol} / 1$ streptomycin, $2 \mathrm{mmol} / 1 \mathrm{~L}$-glutamine at $37^{\circ} \mathrm{C}$ in $5 \% \mathrm{CO}_{2}$ and stimulated with ODNs (one dose of $0.15 \mu \mathrm{g} /$ well), or plasmids (three doses of $3 \mu \mathrm{g} /$ well) or treated with PBS (5 $\mu 1 /$ well). Supernatants were collected after 24 , 30 or $48 \mathrm{~h}$ and stored at $-80^{\circ} \mathrm{C}$ until ELISA analysis.

Measurement of IFN- $\gamma$ production. Supernatants from spleen cell cultures described above were analyzed by ELISA according to the manufacturer's instructions (Biosource, Cliniscience, Montrouge) 24, 30 and $48 \mathrm{~h}$ after stimulation by DNA.

Experimental protocol. For all of the experiments, we used adult (9 week-old) BDIX male rats weighing 200-250 g (Charles River, L'arbresle, France). All the surgical procedures and the care given to the animals were in accordance with institutional guidelines. After anesthetization of the rats, the livers were surgically exposed, and $1.5 \times 10^{6} \mathrm{PROb}$ tumor cells $(100 \mu \mathrm{l})$ were injected under the Glisson's capsule using a 27-gauge needle to generate experimental liver metastases. Fifteen days later, the rats underwent surgery, the livers were exposed, and $100 \mu \mathrm{l}$ of plasmid DNA solution (P or Met-P, $1 \mathrm{mg} / \mathrm{ml}$ ) was directly injected into the tumors by using a $27-$ gauge needle. Twelve (gene expression analysis) or $24 \mathrm{~h}$ (immune cell recruitment analysis) after intratumoral DNA injections, the rats were anesthetized before being sacrificed, and the tumors were removed for analysis. Freshly prepared rat splenocytes without erythrocytes were used for measurement of in vitro IFN- $\gamma$ production. Briefly, rats were sacrificed, and single-cell suspensions were prepared by mechanical dissociation of spleen and erythrocyte lysis by incubating the cells for $10 \mathrm{~min}$ at $4^{\circ} \mathrm{C}$ in buffer $\left(155 \mathrm{mM} \mathrm{NH}_{4} \mathrm{Cl}, 10 \mathrm{mM}\right.$ $\mathrm{NaHCO}_{3}$, and 0.1 mM EDTA, pH 7.4).

Isolation of tumor-infiltrating immune cells. Tumor specimens were pooled (6-12 tumors per experimental group), sliced into small pieces, and digested in DMEM supplemented with $3 \% \mathrm{SVF}, 2 \mathrm{mg} / \mathrm{ml}$ collagenase A, $60 \mu \mathrm{g} / \mathrm{ml}$ DNase I (Roche Molecular Biochemicals, Mannheim, Allemagne) for $2 \mathrm{x}$ $45 \mathrm{~min}$ at $37^{\circ} \mathrm{C}$ with gentle agitation. The resulting cell suspensions were filtered through a nylon membrane and centrifuged for $5 \mathrm{~min}$ at $4^{\circ} \mathrm{C}(400 \mathrm{~g})$. The cells were washed in PBS containing $5 \mu \mathrm{g} / \mathrm{ml}$ DNase I and $3 \%$ SVF, centrifuged for $5 \mathrm{~min}$ at $4^{\circ} \mathrm{C}(400 \mathrm{~g})$, re-suspended in cold PBS containing $50 \mu \mathrm{M}$ EDTA and $3 \% \mathrm{SVF}$, and counted. For flow cytometry analysis, a low-density cell enrichment was performed using Optiprep $^{\mathrm{TM}}$ solution, 1,059 g/l, pH 7.2 (Nyegaard Diagnostics, Oslo, Norway) for $10 \mathrm{~min}$ at $4^{\circ} \mathrm{C}(400 \mathrm{~g})$. The low-density cell fraction was successively depleted in $\gamma \delta \mathrm{T}$ lymphocytes and enriched in $\gamma \delta^{-}$, OX $62^{+}$, conventional dendritic cells using, respectively, mouse anti-rat $\gamma \delta$ TCR and anti-CD103 magnetic bead-coated mAbs according to the manufacturer's instructions (Miltenyi Biotec, Paris, France).

Flow cytometry. The number of conventional activated DCs, plasmacytoid dendritic cells (pDCs), and NK cells in the total tumor cell suspensions was determined by flow cytometry 
analysis following triple stainings with different monoclonal antibodies. Mouse mAbs against $\gamma \delta$ TCR (V65 clone, biotinconjugated), CD86 activation marker (24F clone, biotinconjugated) and CD4 (OX-35 clone, FITC-conjugated) were purchased from BD Biosciences. Mouse mAbs against CD103 (CL083 clone, OX-62, FITC-conjugated), NKR-P1 (CL055 clone, FITC-conjugated) and MHC class II (CL011 clone, RT1.D, PE-conjugated) were purchased from Cedarlane. Tricolor avidin was purchased from Caltag (Burlingame, CA). Mouse $\operatorname{IgG} 1$ and $\operatorname{IgG} 2 \mathrm{a}$ were used as isotype controls. Before specific staining, cell surface Fc receptors were blocked by incubation with purified hyperimmune rat serum (processed in-lab). All the staining steps were performed at $0-4^{\circ} \mathrm{C}$ in PBS containing $5 \mathrm{mM}$ EDTA and $3 \% \mathrm{FCS}$. Analysis was performed on a FACScan flow cytometer (Becton Dickinson \& Co., Mountain View, CA) at the Flow Cytometry Laboratories of IFR50 (Faculty of Medicine, Nice, France) using Cell Quest Pro software (Becton Dickinson).

Immunohistologic analysis. Six-micrometer cryosections of tumors were fixed in acetone for $5 \mathrm{~min}$ at $-20^{\circ} \mathrm{C}$. Endogen biotin was blocked with $5 \%$ goat serum and $10 \%$ streptavidin (Vector Labs, AbCys, Paris, France) in PBS buffer for $30 \mathrm{~min}$ at room temperature, and endogenous peroxidase activity was quenched using $3 \% \mathrm{H}_{2} \mathrm{O}_{2}$ for $10 \mathrm{~min}$ at room temperature. NK cells were detected by overnight incubation at $4^{\circ} \mathrm{C}$ with mouse mAb against NK cells (NKR-P1A, 10-78, Pharmingen, BD Biosciences, Le Pont de Claix, France) in antibody diluent and $10 \%$ biotin (Vector Labs). The isotype antibody (mouse IgG, I-2000, Vector Labs, Burlingame, CA) was used as a negative control. After washing in phosphate-buffered saline, slides were incubated with biotinylated goat anti-mouse immunoglobulins (BD Biosciences, Le Pont de Claix, France) for $1 \mathrm{~h}$ at room temperature, washed, and subsequently incubated with streptavidin-horseradish peroxidase (HRP) conjugate (Pharmingen). After washing, positive cells were visualized using HRP substrate (VIP, Vector Labs). The slides were then counterstained with hematoxylin and treated with mounting medium (VectaMount, Vector Labs) before observation.

RNA extraction. Eight tumors per condition were pooled, and low-density cell enrichment was realized using Optiprep ${ }^{\mathrm{TM}}$ solution $(1,065 \mathrm{~g} / \mathrm{l})$ as previously described. Total RNA of the low-density cell fraction was extracted using Trizol reagent (Invitrogen) according to the manufacturer's instructions. Integrity of the RNA was tested on a $1 \%$ agarose gel, and quantification was carried out by absorption at $260 \mathrm{~nm}$.

RNase protection assay (RPA). RPA was performed with RiboQuant $^{\mathrm{TM}}$ Multi-Probe RNase Protection Assay Kits (BD Biosciences), according to the manufacturer's instructions. Briefly, [ $\left.{ }^{32} \mathrm{P}\right]-$ labeled antisense riboprobes were synthesized with rCK-2 or rCK-3 template set (BD Biosciences), using $2.75 \mathrm{mM}$ GTP, ATP, CTP, $80 \mu \mathrm{Ci}\left[\alpha^{-}{ }^{32} \mathrm{P}\right]-\mathrm{UTP}(3000 \mathrm{Ci} /$ mmol, MP Biomedicals, Vannes, France) and 20 U T7 RNA polymerase. $\left[{ }^{32} \mathrm{P}\right]$-labeled antisense riboprobes were hybridized with $9 \mu \mathrm{g}$ of total RNA of the low-density cell fraction at $56^{\circ} \mathrm{C}$ overnight. After hybridization, $20 \mathrm{ng}$ RNase A and $60 \mathrm{U}$ RNase T1 were added to digest unhybridized RNA for $45 \mathrm{~min}$ at $30^{\circ} \mathrm{C}$. Proteinase $\mathrm{K}(12 \mu \mathrm{g})$ was then added to the sample, and the mixture was incubated at $37^{\circ} \mathrm{C}$ for an additional $15 \mathrm{~min}$. At the end of the incubation, the sample was extracted with phenol/chloroform and ethanol precipitated. The pellet, containing the duplex RNA hybrids was loaded onto a 5\% polyacrylamide gel under denaturating conditions (7 M urea). Gels were dried and exposed to X-ray film at $-70^{\circ} \mathrm{C}$ for varying periods of time. Densitometry analysis was performed using Scion Image software (Scion Corp., Frederick, MD, USA).

Real-time RT-PCR analysis. Genomic DNA was removed by RNase-free DNase (Qiagen), and cDNA was synthesized using $2 \mu \mathrm{g}$ of total RNA of the low-density cell fraction using SuperScript II Reverse Transcriptase and random hexamer primers (Invitrogen) according to the manufacturer's instructions. PCR was performed using an ABI PRISM 7700 Sequence Detection System (Applied Biosystems, Courtaboeuf, France). Reactions were performed in a $20-\mu 1$ volume containing 20- or 40-fold diluted cDNA, $10 \mu \mathrm{l}$ SYBR-Green Master Mix (Applied Biosystems) and $100 \mathrm{nM}$ of each primer according to the protocol provided. The oligonucleotide sequences used were as follows: $\beta$-actin-forward, 5'-GGC CAACCGTGAAAAGATGA-3' and B-actin-reverse, 5'-GAT GGCTACGTACATGGCTGG-3' (accession no. NM_031144, position 339-358 and 388-409); CCR7-forward, 5'-AAC GTGCTGGTGGTGGCT-3' and CCR7-reverse, 5'-CTGTGA CCTCATCTTGGCAGAA-3' (accession no. NM_199489, position 106-126 and 148-180) (Proligo). The reaction was initiated with a denaturation step of $10 \mathrm{~min}$ at $95^{\circ} \mathrm{C}$, followed by 40 cycles, each consisting of $15 \mathrm{sec}$ at $95^{\circ} \mathrm{C}$ and $1 \mathrm{~min}$ at $60^{\circ} \mathrm{C}$. At the end of the reaction, a progressive increase in temperature was performed to analyze putative PCR contaminants. The housekeeping gene $\beta$-actin was used for normalization. Differences in gene expression between the different conditions were calculated using the $2^{-\Delta \mathrm{Ct}}$ method (13).

Statistical analysis. For IFN- $\gamma$ secretion, the results were expressed as the median with $95 \%$ confidence intervals (CI), and comparisons were performed using the Mann-Whitney test, which is a non-parametric, two-tailed probability test. The statistics were computed with Minitab ${ }^{\mathrm{TM}}$ Inc. V12.2 (State College, PA, USA). p values were considered to be statistically significant when $<0.05$.

\section{Results and discussion}

To determine whether the pCDßgeo plasmid carried functional immunostimulatory $\mathrm{CpG}$ sequences, we analyzed the plasmidinduced IFN- $\gamma$ secretion by splenocytes. Rat spleen cells, which constitute a CpG-responsive population (5), were cultured in the presence of native plasmid (P) or SssImethylated plasmid (Met-P), in which the effect of $\mathrm{CpG}$ sequences had been abolished by methylation, or CpG-ODN stabilized by a phosphorothioate backbone used as a positive control. The medium of the negative control cultures was supplemented with PBS or with non-CpG-ODN (CpC). At 


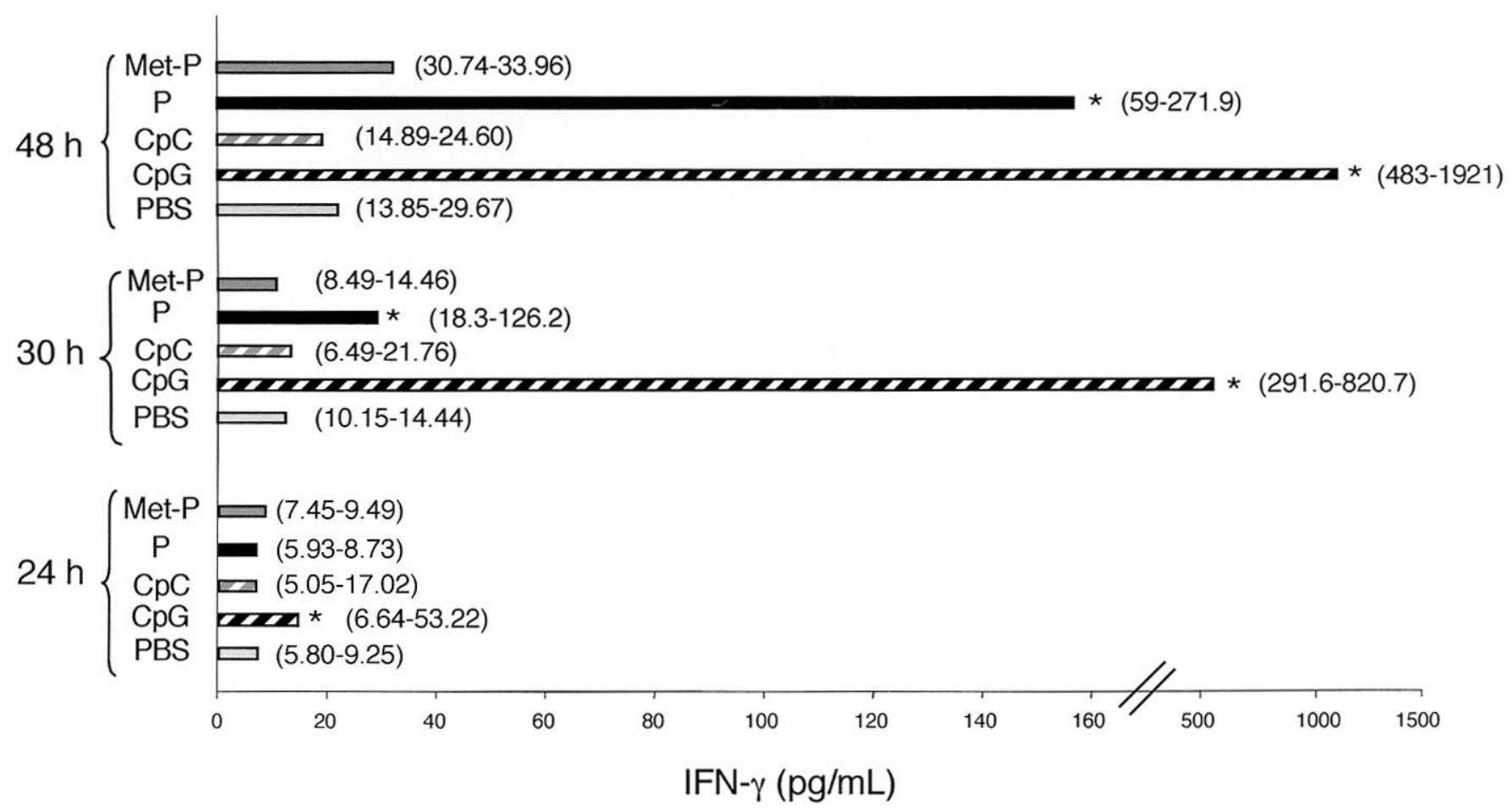

Figure 1. Analysis of IFN- $\gamma$ secretion in rat spleen cells cultured in the presence of native or methylated pCDßgeo plasmid. Rat spleen cells $\left(10^{6}\right)$ were cultured in the presence of $\mathrm{CpG}-\mathrm{ODN}(\mathrm{CpG})$ or native (P) or methylated (Met-P) pCDßgeo plasmid for 24, 30 and 48 h. Cultures in the presence of PBS or $\mathrm{CpC}-\mathrm{ODN}(\mathrm{CpC})$, devoid of $\mathrm{CpG}$ immunostimulatory motifs, were used as negative controls. Bars represent the median IFN- $\gamma$ secretion from 4 to 8 ELISA wells in each condition with $95 \%$ confidence intervals. ${ }^{*} \mathrm{p}<0.05$, significant difference compared to the PBS condition.

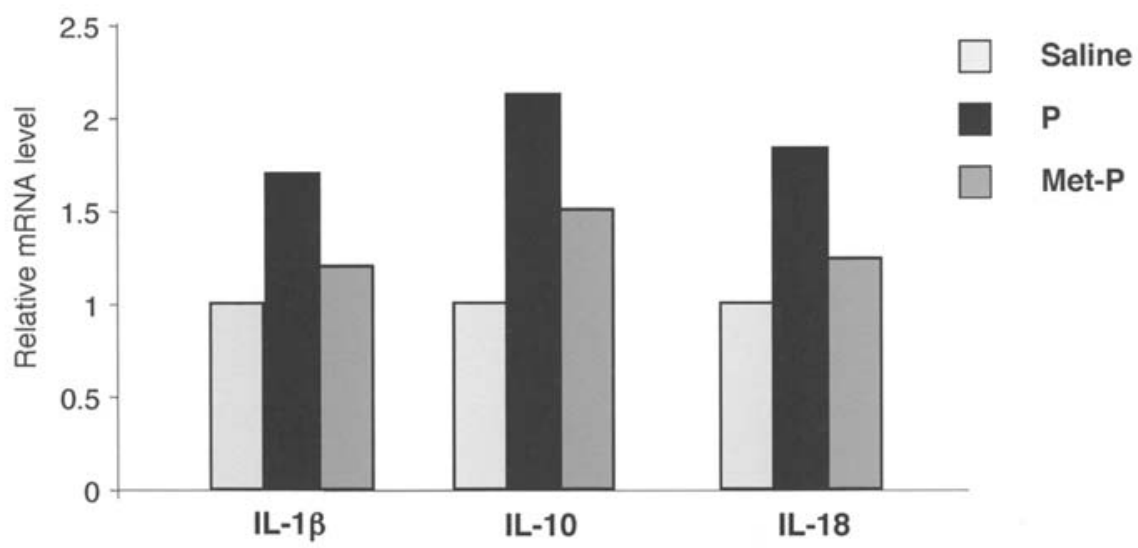

Figure 2. Analysis of cytokine/chemokine mRNA expression following plasmidic CpG intratumoral injection. The cytokine microenvironment analysis of the tumor by RNase Protection Assay. Twelve hours after saline, P or Met-P injection, 8 tumors per condition were pooled, and a population enriched in tumorinfiltrating immune cells was isolated by selection of low-density cells. Total RNA was extracted from these cells, and the Multi-Probe RNase Protection Assay was performed to determine the mRNA expression of different cytokines/chemokines. The results are expressed as the ratio of the studied gene relative to L32 which encodes a ubiquitously expressed ribosome subunit protein used as an internal control for normalization. Mean values obtained in the saline condition were assigned the value of 1 (arbitrary units).

different time points, the supernatants were collected and analyzed by ELISA. As shown in Fig. 1, culturing with CpGODN induced, respectively, a 2- $(\mathrm{p}=0.01), 46-(\mathrm{p}=0.005)$ and 50 -fold $(\mathrm{p}=0.03)$ increase in IFN- $\gamma$ secretion after 24,30 and $48 \mathrm{~h}$, compared to PBS-treated cultures. The presence of native plasmid within the culture for 30 and $48 \mathrm{~h}$ induced, respectively, a 2- $(\mathrm{p}=0.005)$ and 7 -fold $(\mathrm{p}=0.03)$ increase in IFN- $\gamma$ production compared to PBS or methylated plasmid treatments. There was no significant difference between PBS, Met-P and CpC-ODN treatments. These results indicate that the pCDßgeo plasmid contained active $\mathrm{CpG}$ sequences which were able to stimulate rat immune cells.

To analyze whether the presence of plasmidic $\mathrm{CpG}$ sequences was associated with a modification in cytokine/ chemokine microenvironment in vivo, experimental liver metastases were generated in rats, and $\mathrm{P}$, Met-P or saline was intratumorally injected. Twelve hours post-injection, the rats were sacrificed, and the tumors were removed. Eight tumors in each experimental group were pooled and enzymatically dissociated, and a low-density cell fraction containing an 
A

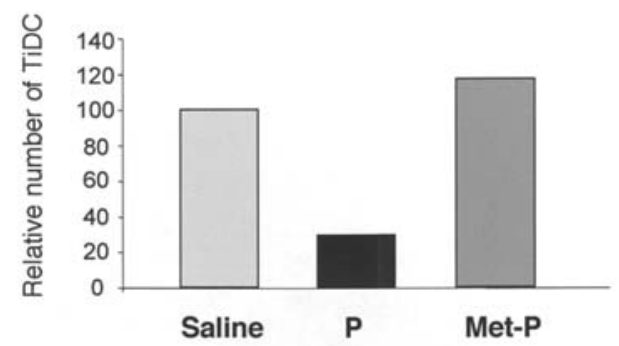

B

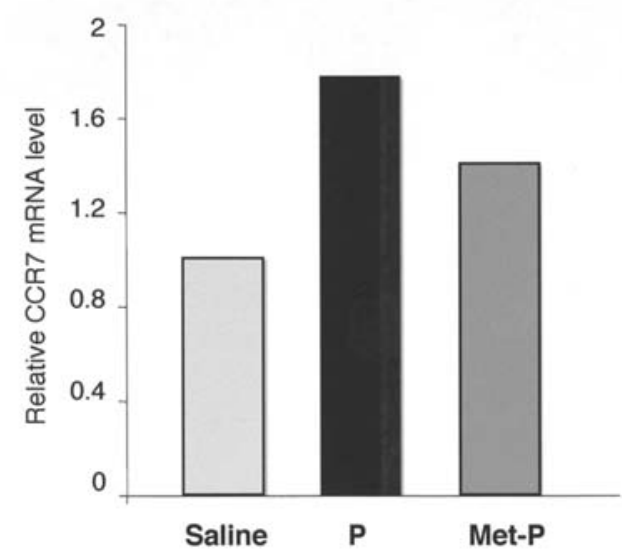

Figure 3. Analysis of tumor-infiltrating dendritic cells after plasmidic CpG injection. Twenty-four hours after saline, $\mathrm{P}$ or Met-P intratumoral injection, the experimental liver metastases were pooled and dissociated, and a population enriched in tumor-infiltrating immune cells was isolated by selection of low-density cells. (A) The relative number of tumor-infiltrating conventional dendritic cells (TiDC). Low-density cells were depleted in $\gamma \delta$ $\mathrm{T}$ lymphocytes, and $\mathrm{OX} 62^{+}$cells were then enriched using mAb-coated magnetic beads. The selected population was labeled with anti-OX62, -MHC II and -CD86 antibodies and analyzed by flow cytometry. The relative number of TiDCs in each experimental condition corresponded to the number of $\mathrm{OX} 62^{+}, \mathrm{MHC} \mathrm{II}^{+}, \mathrm{CD}^{+} 6^{+}$conventional activated DCs normalized to the same number of total cells within the tumors. The results obtained in the saline condition were assigned the value of $100 \%$ (arbitrary units). Data are representative of three independent experiments. (B) RT-PCR analysis of CCR7 mRNA expression. Messenger RNA from the populations enriched in tumor-infiltrating immune cells were analyzed by RT-PCR using B-actin as an internal standard $12 \mathrm{~h}$ after saline, $\mathrm{P}$ or Met-P intratumoral injection. The results obtained in the saline condition were assigned the value of 1 (arbitrary units).

enriched tumor-infiltrating immune cell population was isolated. Determination of mRNA expression for 18 cytokines/chemokines was then performed in this enriched cell population. The relative expression level of the modulated cytokines/chemokines in the different experimental groups is presented in Fig. 2. Intratumoral administration of native plasmid DNA induced a 40, 40 and $50 \%$ increase in IL-1ß, IL-10 and IL-18 mRNA expression levels, respectively, compared to Met-P-injected tumors. The expression levels for IL-12p35, IL-12p40, IFN- $\beta$ and TGF- 33 were below the detection limit independent of the testing condition, and no significant modulation of IL-1 $\alpha$, IL-1-Ra, IL- 6 , IFN- $\gamma$, TNF- $\alpha$,
TGF- $\beta 1$, TGF- $\beta 2$, LT- $\alpha$, LT- $\beta$, GM-CSF and MIF mRNA expression was observed. IL-1ß and IL-18 are proinflammatory cytokines secreted as proforms requiring caspase 1 cleavage for activation (14), and we observed an increase in caspase 1 expression in these tumors (unpublished data). Although bacterial $\mathrm{CpG}$ motifs are essentially known as potent inducers of proinflammatory cytokines such as IL-1ß and IL-18, production of the anti-inflammatory cytokine IL-10 was recently reported following $\mathrm{CpG}$ stimulation $(15,16)$. These observations suggest the existence of a two-step model where the initial TLR signaling induced pro-inflammatory cytokines, and then IL-10, thereby influencing the ensuing immune responses (15).

We further explored the influence of the plasmidic unmethylated $\mathrm{CpG}$ sequences within tumors in vivo, by analyzing the presence of conventional dendritic cells (DCs), plasmacytoid dendritic cells (pDCs) and natural killer (NK) cells, $24 \mathrm{~h}$ after $\mathrm{P}$, Met-P or saline intratumoral injection. We first analyzed low-density $\gamma \delta^{-}, \mathrm{OX}^{+} 2^{+}, \mathrm{MHCII}^{+}$, and $\mathrm{CD}^{\circ} 6^{+}$ cells corresponding to rat activated conventional DCs (17). As shown in Fig. 3A, the presence of plasmidic $\mathrm{CpG}$ motifs was associated with a 70 and $85 \%$ decrease in the number of tumor-infiltrating DCs (TiDCs) compared to saline and Met$\mathrm{P}$ conditions, respectively. To assess whether the decreased number of TiDCs in the native plasmid-injected tumors was related to an enhanced migratory activity towards draining lymph nodes, we analyzed mRNA expression of the CCR7 chemokine receptor in tumor-infiltrating immune cells by real-time RT-PCR. As shown in Fig. 3B, we observed a 77 and $40 \%$ increase in mRNA expression in $\mathrm{P}$ - compared to saline- and Met-P-injected tumors, respectively. This upregulation of the CCR7 chemokine receptor responsible for lymph node homing (18) suggests that the presence of plasmidic CpG motifs induces dendritic cell activation and migration from the tumor to the lymph nodes. These findings are consistent with previous observations obtained after in vivo administration of different TLR ligands such as LPS, imiquimod or resiquimod, leading to the emigration of dendritic cells from the liver, intestine lamina propria or skin towards draining lymph nodes (19-21).

As pDCs represent a major CpG-responsive immune cell population (22), we next analyzed the number of OX62-, $\mathrm{CD}^{+}, \mathrm{MHCII}^{+}$, and $\mathrm{CD}^{+} 6^{+}$cells, corresponding to $\mathrm{pDCs}$ in rats (23). Twenty-four hours after DNA administration, we observed a 100 and $130 \%$ increase in the pDC number in Pcompared to saline- and Met-P-injected tumors, respectively (Fig. 4A). Similarly, the number of tumor-infiltrating NK cells was increase by 190 and 100\%, $24 \mathrm{~h}$ after native plasmid compared to saline and methylated plasmid injection, respectively (Fig. 4B). These last results were confirmed $24 \mathrm{~h}$ after DNA injection by immunohistologic analysis of the tumors. As shown in Fig. 4C, only a few NK cells were present within the saline- or methylated plasmid-treated tumors, whereas tumors injected with native plasmid were heavily infiltrated by this cell type. As IL-18 has been described to attract pDCs (24) which are known to produce chemokines inducing NK cell migration (25), we can thus speculate that plasmidic $\mathrm{CpG}$ motifs induce IL-18 expression, leading to $\mathrm{pDC}$ recruitment which in turn attracts NK cells. 
A

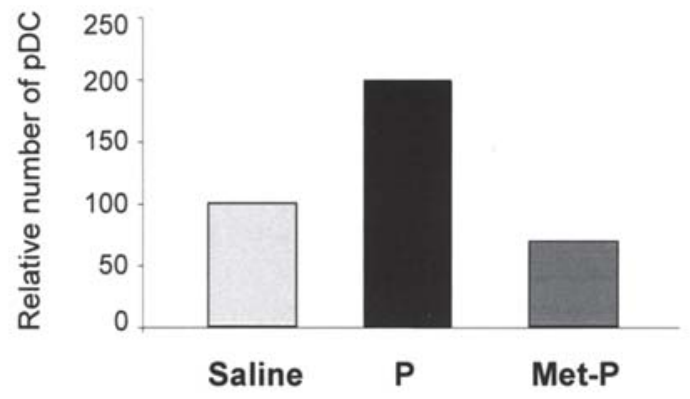

B

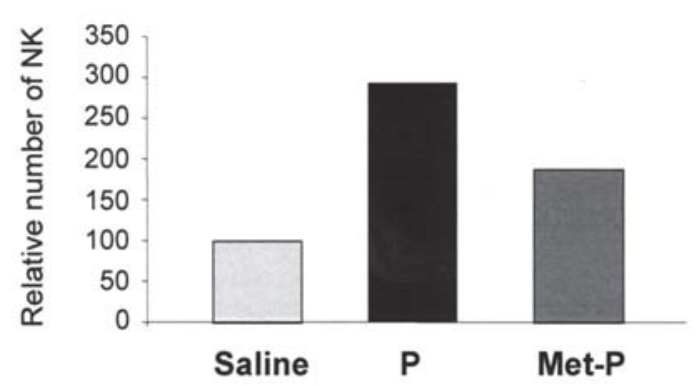

C
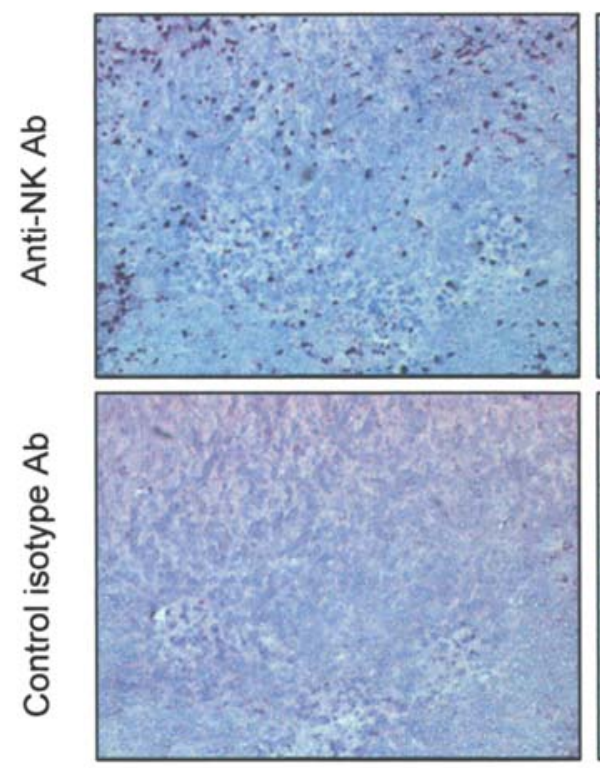

$\mathbf{P}$
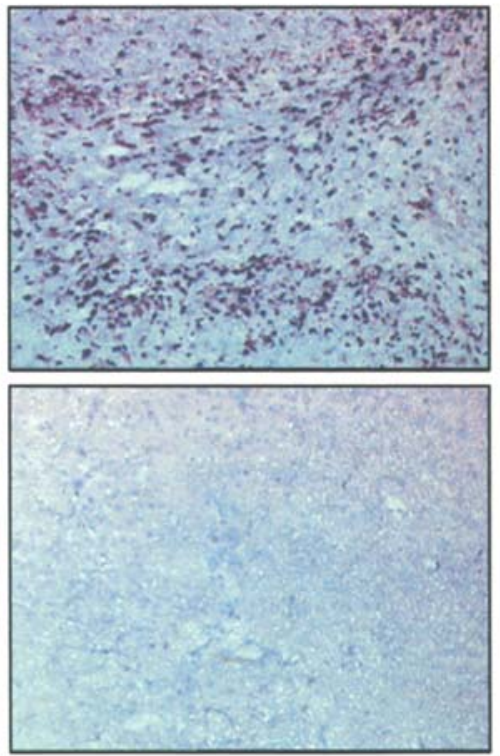

Met-P
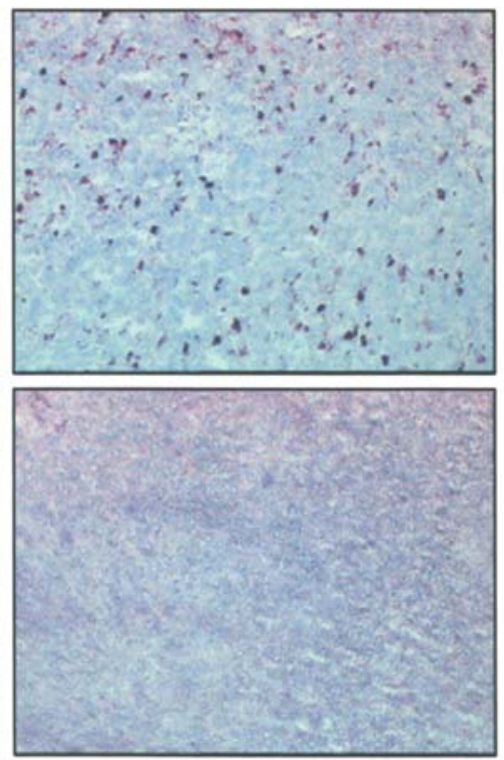

Figure 4. Analysis of tumor-infiltrating plasmacytoid dendritic cells (pDC) and natural killer (NK) cells after plasmidic CpG injection. Twenty-four hours after saline, $\mathrm{P}$ or Met-P intratumoral injection, the experimental liver metastases were pooled and dissociated, and a population enriched in tumor-infiltrating immune cells was isolated by selection of low-density cells. (A) The relative number of tumor-infiltrating plasmacytoid dendritic cells. OX62- low-density cells were isolated using anti-CD4-coated magnetic beads. The selected population was labeled with anti-CD4, -MHC II and -CD86 antibodies and analyzed by flow cytometry. The relative number of pDCs in each experimental condition corresponded to the number of $\mathrm{CD}^{+}, \mathrm{MHC}^{+}$, and $\mathrm{CD} 6^{+}$cells normalized to the same number of total cells within the tumors. The results obtained in the saline condition were assigned the value of $100 \%$ (arbitrary units). Data are representative of three independent experiments. (B) The relative number of tumor-infiltrating NK cells. OX62- low-density cells were enriched in NK cells using anti-NK-coated magnetic beads. The selected population was then labeled with anti-NK, -MHC II and - $\gamma \delta$ antibodies and analyzed by flow cytometry. The relative number of $\mathrm{NK}$ cells in each experimental condition corresponded to the number of $\mathrm{NK}^{+}, \mathrm{MHC}^{-} \mathrm{II}^{-}$, and $\gamma \delta^{-}$cells normalized to the same number of total cells within the tumors. The results obtained in the saline condition were assigned the value of 100\% (arbitrary units). Data are representative of three independent experiments. (C) Immunohistologic analysis of tumor cryosections $24 \mathrm{~h}$ after saline, $\mathrm{P}$ or Met-P intratumoral injection. Upper panels, immunolabeling of NK cells. Lower panels, immunolabeling of corresponding sections with secondary antibodies alone. Original magnification for all panels, $\mathrm{x} 10$.

In addition to cancer cell destruction allowing tumor antigen release, an optimal antitumor immune response requires recruitment and activation of immune cells, creation of a proinflammatory environment and the presence of danger signals $(26,27)$. Taken together, our data suggest that bacterial CpG motifs present in plasmid DNA are involved in 
the generation of a tumor microenvironment facilitating the triggering of an antitumoral immune response.

\section{Acknowledgements}

We thank Dr Pascal Staccini (Département Informatique Médicale, Faculté de Médecine, Nice) for the statistical analysis of the results. This work was supported by the Institut National de la Santé et de la Recherche Médicale, Fondation de l'Avenir, France Cancer and Association pour la Recherche sur le Cancer.

\section{References}

1. Consensus conference: Prevention Screening and Management of the Colonic Cancers. Paris, France, January 29-30, 1998. Proceedings. Gastroenterol Clin Biol 22: S1-S295, 1998.

2. Jaeck D and Bachellier P: Colonic cancers with visceral metastasis (synchronous or metachronous): which surgical treatment to offer? Gastroenterol Clin Biol 22: S168-S176, 1998.

3. Pierrefite-Carle V, Baqué P, Gavelli A, et al: Cytosine deaminase/5-fluorocytosine-based vaccination against liver tumors: evidence of distant bystander effect. J Natl Cancer Inst 91: 2014-2019, 1999.

4. Baqué P, Pierrefite-Carle V, Gavelli A, et al: Naked DNA injection for liver metastases treatment in rats. Hepatology 35: 1144-1152, 2002.

5. Krieg AM: CpG motifs in bacterial DNA and their immune effects. Annu Rev Immunol 20: 709-760, 2002.

6. Hemmi H, Takeuchi O, Kawai T, et al: A Toll-like receptor recognizes bacterial DNA. Nature 408: 740-745, 2000.

7. Takeshita F, Gursel I, Ishii KJ, Suzuki K, Gursel M and Klinman DM: Signal transduction pathways mediated by the interaction of $\mathrm{CpG}$ DNA with Toll-like receptor 9. Semin Immunol 16: 17-22, 2004.

8. Sfondrini L, Besusso D, Rumio C, Rodolfo M, Menard S and Balsari A: Prevention of spontaneous mammary adenocarcinoma in HER-2/neu transgenic mice by foreign DNA. FASEB J 16: 1749-1754, 2002.

9. Carpentier AF, Xie J, Mokhtari K and Delattre JY: Successful treatment of intracranial gliomas in rat by oligodeoxynucleotides containing $\mathrm{CpG}$ motifs. Clin Cancer Res 6: 2469-2473, 2000.

10. Heckelsmiller K, Beck S, Rall K, et al: Combined dendritic celland $\mathrm{CpG}$ oligonucleotide-based immune therapy cures large murine tumors that resist chemotherapy. Eur J Immunol 32: 3235-3245, 2002.

11. Kawarada Y, Ganss R, Garbi N, Sacher T, Arnold B and Hammerling GJ: $\mathrm{NK}^{-}$and $\mathrm{CD} 8(+) \mathrm{T}$ cell-mediated eradication of established tumors by peritumoral injection of CpGcontaining oligodeoxynucleotides. J Immunol 167: 5247-5253, 2001 .
12. Martin F, Caignard A, Jeannin JF, Leclerc A and Martin M: Selection by trypsin of two sublines of rat colon cancer cells forming progressive or regressive tumors. Int J Cancer 32: 623-627, 1983.

13. Livak KJ and Schmittgen TD: Analysis of relative gene expression data using real-time quantitative PCR and the 2(-Delta Delta C(T)) method. Methods 25: 402-408, 2001.

14. Mariathasan S and Monack DM: Inflammasome adaptors and sensors: intracellular regulators of infection and inflammation. Nat Rev Immunol 7: 31-40, 2007.

15. Samarasinghe R, Tailor P, Tamura T, Kaisho T, Akira S and Ozato K: Induction of an anti-inflammatory cytokine, IL-10, in dendritic cells after toll-like receptor signaling. J Interferon Cytokine Res 26: 893-900, 2006.

16. Flores RR, Diggs KA, Tait LM and Morel PA: IFN-gamma negatively regulates $\mathrm{CpG}$-induced IL-10 in bone marrowderived dendritic cells. J Immunol 178: 211-218, 2007.

17. Brenan M and Puklavec M: The MRC OX-62 antigen: a useful marker in the purification of rat veiled cells with the biochemical properties of an integrin. J Exp Med 175: 1457-1465, 1992.

18. Sanchez-Sanchez N, Riol-Blanco L and Rodriguez-Fernandez JL: The multiple personalities of the chemokine receptor CCR7 in dendritic cells. J Immunol 176: 5153-5159, 2006.

19. Turnbull EL, Yrlid U, Jenkins CD and MacPherson GG: Intestinal dendritic cell subsets: differential effects of systemic TLR4 stimulation on migratory fate and activation in vivo. J Immunol 174: 1374-1384, 2005.

20. Yrlid U, Milling SW, Miller JL, Cartland S, Jenkins CD and MacPherson GG: Regulation of intestinal dendritic cell migration and activation by plasmacytoid dendritic cells, TNF-alpha and type 1 IFNs after feeding a TLR7/8 ligand. J Immunol 176: 5205-5212, 2006.

21. Suzuki H, Wang B, Shivji GM, et al: Imiquimod, a topical immune response modifier, induces migration of Langerhans cells. J Invest Dermatol 114: 135-141, 2000.

22. Klinman DM: Adjuvant activity of CpG oligodeoxynucleotides. Int Rev Immunol 25: 135-154, 2006.

23. Hubert FX, Voisine C, Louvet C, Heslan M and Josien R: Rat plasmacytoid dendritic cells are an abundant subset of $\mathrm{MHC}$ class $\mathrm{II}^{+} \mathrm{CD}^{+}{ }^{+} \mathrm{CD} 11 \mathrm{~b}^{-} \mathrm{OX} 62^{-}$and type I IFN-producing cells that exhibit selective expression of Toll-like receptors 7 and 9 and strong responsiveness to CpG. J Immunol 172: 7485-7494, 2004.

24. Kaser A, Kaser S, Kaneider NC, Enrich B, Wiedermann CJ and Tilg H: Interleukin-18 attracts plasmacytoid dendritic cells (DC2s) and promotes Th1 induction by DC2s through IL-18 receptor expression. Blood 103: 648-655, 2004

25. Megjugorac NJ, Young HA, Amrute SB, Olshalsky SL and Fitzgerald-Bocarsly P: Virally stimulated plasmacytoid dendritic cells produce chemokines and induce migration of $\mathrm{T}$ and $\mathrm{NK}$ cells. J Leukoc Biol 75: 504-514, 2004.

26. Gallucci S and Matzinger P: Danger signals: SOS to the immune system. Curr Opin Immunol 13: 114-119, 2001.

27. Matzinger P: The danger model: a renewed sense of self. Science 296: 301-305, 2002. 